\title{
Utopía versus pragmatismo urbanístico en la ciudad española del siglo XXI
}

\author{
Basilio Calderón. Universidad de Valladolid, Valladolid, España. \\ José-Luis García-Cuesta. Universidad de Valladolid, Valladolid, España.
}

RESUMEN | Como consecuencia de la crisis económica e inmobiliaria de la primera década del siglo xxi, todos los sistemas urbanos han visto cómo se agotaba el modelo de crecimiento urbano indefinido, se multiplicaban los problemas de carácter económico, social o medioambiental, y se comenzaban a ensayar algunas soluciones, entre utópicas y pragmáticas, para afrontarlos. Tras una aproximación inicial a las similitudes y diferencias entre las distopías y utopías urbanas de los siglos XIX y xx, se hace a continuación una reflexión acerca del significado de estas últimas en la ciudad española, en las dos primeras décadas del siglo xxi. Con tal objeto, en los siguientes apartados se ha tratado de oponer el carácter pionero e incipiente de las utopías urbanas que hemos denominado inteligentes y sostenibles, a la madurez y pragmatismo de las viejas y convencionales soluciones sociourbanísticas, ya sean de renovación por desposesión, o de integración mediante operaciones de regeneración.

PALABRAS CLAVE | estructura urbana, sustentabilidad urbana, renovación urbana.

ABSTRACT | As a consequence of the economic and housing crisis of the first decade of the 21 st century, all the urban systems have seen the limitless urban growth model fail, while the economic, social and environmental problems have multiplied. Some different models, half way between utopian and pragmatic, have been discussed as possible solutions. Following an initial approach to the similarities and differences between the urban dystopias and utopias of the 19th and 20th centuries, a reflection is offered concerning the meaning of the latter in Spanish cities over the first two decades of the 21st century. To this end, in the following sections, the pioneering and incipient character of the urban utopias, which we have called intelligent and sustainable, have been compared with the maturity and pragmatism of the old, conventional socio-urbanistic solutions, whether they embrace renovation through dispossession or integration through regeneration operations.

KEYWORDS | urban structure, urban sustainability, urban renewal. 


\section{Introducción}

El proceso de creación, crecimiento y transformación de la ciudad, es decir, el ciclo de vida útil de la edificación e infraestructuras, la forma en que se aborda su reforma o renovación y los cambios de paradigma, determinan los rasgos de cada periodo en la historia de la ciudad. Tradicionalmente, todos ellos eran muy estables y, por lo tanto, el modelo y paisaje de ciudad también lo era, pero en las dos últimas décadas interseculares, hemos asistido a una acelerada sucesión de los dos grandes paradigmas, es decir, de teorías cuyo núcleo central se acepta sin cuestionar, sobre la intervención y el futuro de la ciudad: crecer, desordenar las periferias y abandonar el centro; y su opuesto, limitar el crecimiento y volver a recuperar, por generación o renovación, la ciudad heredada.

El responsable último de la cíclica alternancia de paradigmas ha sido el planeamiento, en tanto que vehículo de una determinada política en materia de suelo. En lo que a la ciudad respecta, nos movemos entre dos paradigmas o modelos: por una parte, el crecimiento expansivo, que va dejando detrás una ciudad vieja, deteriorada y parcialmente abandonada (Álvarez Mora, 2015); y por otra parte, el paradigma rehabilitador, regenerador y renovador que, al incorporar -no puede ser de otro modo- todos los postulados de la Unión Europea sobre sostenibilidad, encuentra la justificación social y legal para volver a intervenir en la vieja ciudad, reproduciendo un fenómeno que ya había pasado otras veces en la historia reciente de la ciudad europea, y de la española en particular. Evidentemente, existen yuxtaposiciones de las soluciones que aporta cada paradigma; la ciudad no se transforma por implementación de modelos excluyentes. Los paradigmas coexisten, si bien es la dinámica y plazos de la normativa y del planeamiento los que acaban imponiendo a uno sobre otro, aunque transcurran para alcanzar este objetivo -si se llega a alcanzar- muchos años o décadas.

El primero de estos paradigmas fue impulsado en España por la legislación sobre el suelo promulgada entre 1998 y 2007, ya que en ella se reconocía que hacer ciudad consistía, esencialmente, en explotar la multiplicación que se opera en el valor de los terrenos al hacerlos urbanizables (Burriel, 2008), favoreciendo con ello una sola opción: la ocupación-colonización de nuevos suelos y su construcción, frente a la conservación del patrimonio ya construido (Fariña \& Naredo, 2010). Consecuentemente, toda la legislación española finisecular, al igual que en otros muchos países, siguió contemplando la ciudad como un territorio vacío en el cual ubicar nuevos e ilimitados aprovechamientos residenciales o terciarios, que se justificaban no tanto por su necesidad real, sino por la superioridad económico-cultural de la nueva urbanización en relación con la recuperación de la ciudad construida o la protección del suelo dotado de valores agrarios o ambientales (Naredo, 2010).

Con una legislación tan favorable a la expansión urbana, gestionada por la gran promoción inmobiliaria, fue relativamente sencillo desplegar agresivas estrategias de ocupación de nuevo suelo por parte del sector privado, dando lugar a una completa desarticulación del modelo de crecimiento y estructura urbana heredados (Serrano, 2010). Asimismo, estos excesos urbanístico-inmobiliarios, bien documentados en la literatura académica del momento (Brandis, 2012; Burriel, 2008; Campesino, 2014; 
Gaja, 2015a; Lois, Piñeira \& Vives, 2016; Mata, 2007; Nel.lo, 1998; Precedo \& Mínguez, 2014; Romero, 2010; Romero, Brandis \& Melo, 2015), se tradujeron en una ruptura de la contigüidad de la ciudad-aglomeración clásica; y esta nueva ciudad, suma de discontinuidades, es en gran medida distópica, económica y ecológicamente insostenible, alentando alternativas más o menos pragmáticas sobre la base de las nuevas ecoutopías, dominantes como paradigma a escala internacional, $\mathrm{y}$ del que fue un buen ejemplo la respuesta que, al finalizar el siglo $\mathrm{xx}$, se dio en algunos estados y ciudades de Estados Unidos al crecimiento periférico de baja densidad (urban sprawl), mediante el desarrollo de los principios del llamado crecimiento inteligente o smart growth (Downs, 2005).

La quiebra de este modelo hiperconstructor, tras la crisis de 2007, hizo aflorar los altos costes no percibidos del sistema; es decir, un conjunto de manifestaciones distópicas, tales como los costes de desplazamiento, las urbanizaciones inacabadas e infradotadas, la insostenibilidad económica, el déficit y deuda pública y privada, la crisis del sistema de financiación (Cajas de Ahorro), el sobreesfuerzo financiero de las familias, los desahucios y la pérdida del valor de la propiedad, la tugurización, etcétera (Méndez \& Plaza, 2016). Constatadas todas ellas, la ciudad habría llegado al final de una trayectoria expansiva, para comenzar a trazar un viaje de vuelta, en sentido contrario; describe por ello un recorrido en forma de vaivén, impulsado, en cierto modo, por una legislación urbanística y planes de vivienda del periodo 19982016, dotados de una alta capacidad para imponer nuevos paradigmas relacionados con las formas de crecimiento urbano (Calderón, 2012).

Este movimiento de retorno está asociado a diversas propuestas para recuperar la ciudad, ya sea la ciudad ideal, para lo cual hay que desviarse de la trayectoria original, o la ciudad posible, aplicando diversas soluciones, llamadas inteligentes, para no cuestionar radicalmente los fundamentos del sistema inmobiliario. Pero con una particularidad: una mayor y muy regulada conciencia ambiental puede estar camuflando, otra vez, una nueva estrategia de apropiación de valores urbanos — con la consiguiente exclusión social—, vinculada ahora a la rehabilitación, regeneración y renovación del tejido histórico de la ciudad, tras el boom y la crisis de las grandes promociones de las periferias urbanas desarrolladas entre 1997 y 2007.

Para demostrar esta hipótesis sobre la efímera vida de estos dos grandes paradigmas urbanos y su recurrente oscilación entre extremos irreconciliables —entre centro y periferia, entre distopías y utopías—, se ha utilizado el método de comparación entre aquellas que tienen carácter global, de las que participa el conjunto del sistema urbano mundial en los dos últimos periodos interseculares: siglos XIX al $\mathrm{xx}$ y siglos $\mathrm{xx}$ al XxI. El objetivo es resaltar las similitudes y diferencias de las soluciones urbanísticas y edificatorias, utópicas o pragmáticas de la ciudad española, al comienzo del tercer milenio.

Asimismo, se ha consultado la información estadística disponible del conjunto de los municipios españoles, a partir de la explotación de los datos del Atlas Digital de las Áreas Urbanas Españolas, actualizado en el año 2016; del catálogo de barrios vulnerables y de las características de la edificación residencial de 2011; así como las series estadísticas del Ministerio de Fomento sobre vivienda protegida, vivienda 
libre, estimación del parque de viviendas, stock de vivienda nueva, transacciones inmobiliarias, valor tasado de la vivienda y precios del suelo urbano. ${ }^{1}$

Con esta información y partiendo de una reflexión sobre la relación entre distopías y nuevas utopías urbanas, se trata de valorar el significado de estas últimas en la ciudad española, a lo largo de las dos primeras décadas del siglo xxi; tratando de oponer el carácter pionero de las utopías urbanas inteligentes y sostenibles, a la madurez y pragmatismo de las tradicionales y convencionales soluciones renovadoras y regeneradoras de la ciudad. Expresado de otra manera, trataremos de demostrar que la alternativa a la ciudad, en forma de nuevas ciudades (o barriosciudad) más o menos utópicas o irrealizables, se ha visto superada por la necesidad de afrontar, con carácter realista y pragmático, los problemas que afectan a la ciudad del siglo xxi. Se procura con ello una intervención menos agresiva y consumista, es decir, más sostenible, implementando diversos programas de regeneración y rehabilitación que conforman, tras la crisis, el paradigma alternativo a la ciudad de crecimiento indefinido de las décadas anteriores.

\section{Alternativas a la ciudad como distopía global: entre la utopía y el pragmatismo}

El sistemático e implacable proceso de crecimiento urbano registrado a lo largo del siglo xx, que ha llevado a más de la mitad de la población del planeta a vivir en las ciudades, no ha sido ni homogéneo en su distribución regional ni neutro en sus consecuencias; al contrario, ha estado históricamente asociado a la aparición y sucesión de diversas patologías - problemas- en materia de infraestructuras, transporte, vivienda, y también de tipo económico y social, tales como desempleo, desarraigo, segregación social y residencial y, en casos extremos, explotación laboral, desigualdad, miseria y hambre (Button \& Schuller, 2016). La respuesta a todas ellas ha sido históricamente ambivalente. En el tránsito del siglo xIx al xx, gran parte de las alternativas derivaron hacia la representación imaginativa de una sociedad futura de características favorecedoras del bien humano, es decir, hacia la formulación de alternativas extramuros, en los márgenes de la ciudad, en forma de planes, proyectos, doctrinas o sistemas deseables que parecen de muy difícil realización; es decir, utópicos, según la acepción que a este término se da en el diccionario de la Real Academia de la Lengua Española (Capel, 2016).

Este es el espíritu que anima los fundamentos del igualitarismo, anarquismo, socialismo, comunismo, presentes en las obras de Henri de Saint-Simon, Charles Fourier, Victor Considerant, Friedrich Engels, Karl Marx, Flora Tristan, Étienne Cabet, Graco Babeuf, Filippo Buonarroti, Auguste Blanqui o Henry George, entre otros (Benevolo, 1976). En todas ellas, la ciudad industrial decimonónica se describe en términos apocalípticos, asociándose la crisis de la misma con la crisis de la civilización conocida (Castro, 2010; Rodríguez, 2005), para justificar, de este modo, diversas fórmulas de huida a la Arcadia, un lugar imaginado, caracterizado

$1 \longdiv { \text { Ministerio de Fomento, Gobierno de España: Información estadística | Vivienda y actuaciones } }$ urbanas. En http://bit.ly/2gsEuTz 
por la vida sencilla, la ausencia de conflicto, la integración en la naturaleza o la fraternidad, lejos de las carencias y conflictos asociados a la que más tarde, en 1961 y en la obra The City in History, Lewis Mumford denominó "Ciudad Carbón".

Pertenecen también a este grupo otras alternativas utópicas en las que se combina el ideal social con la ciudad ideal, como la ciudad industrial de Tony Garnier, de 1901, o la propuesta de desarrollo urbano Broadacre City, recogida en la obra de Frank Lloyd Wright The Disappearing City, publicada en el año 1932, e incluso La ciudad voladora, de Gueorgui Krútikov, obra publicada en 1928 y que es el paradigma de las ideas visionarias para responder a la sobreexplotación del planeta, modelo propio de las vanguardias de los ańos veinte y treinta del siglo xx en Europa. En cierto modo, la utopía social primigenia se fue impregnando de soluciones formales, técnicas, de enorme atractivo urbanístico académico-disciplinar, pero de aplicación formal imposible; una frustración que se comparte si se analizan las cualidades de las soluciones que el utopismo contemporáneo trata de aplicar a la ciudad: caras y elitistas (Carreras \& Moncuende, 2016; Frago \& Martínez, 2016).

FIGURA I | El motor del crecimiento urbano: estímulo y respuesta, distopías y utopías

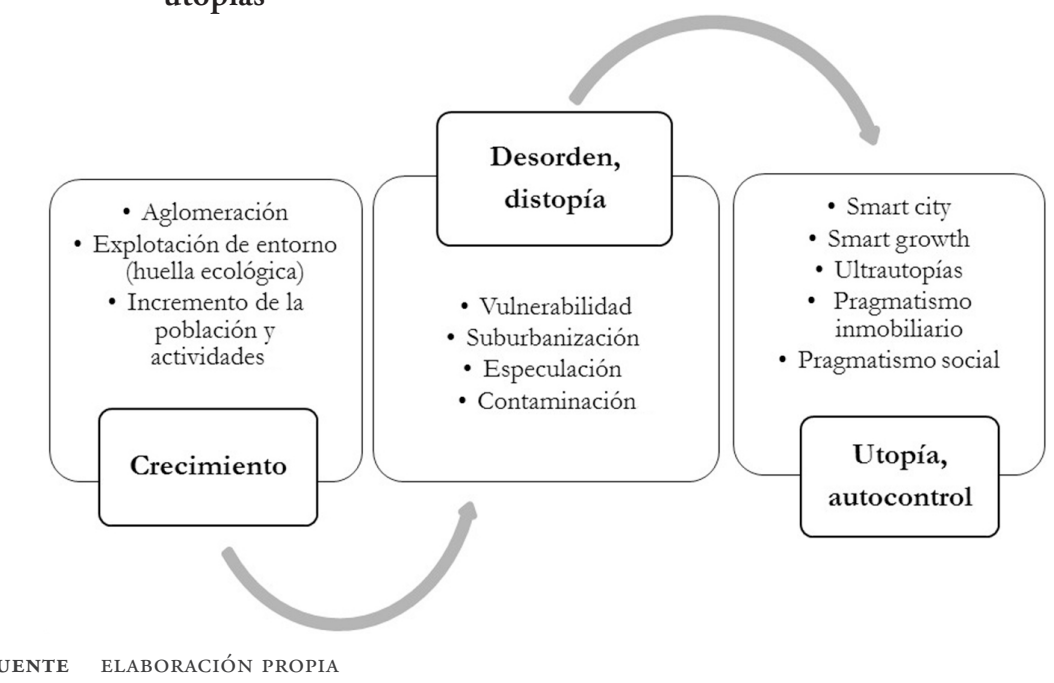

Otro conjunto de respuestas procuró la búsqueda de soluciones internas, realistas, pragmáticas o antiutópicas, en aplicación no declarada de la ley de estímulo-respuesta, según la cual se da a los problemas de la ciudad, superado un determinado umbral -ley del umbral-, una doble respuesta institucional: por una parte, de carácter asistencial y remedial, revestida habitualmente de filantropía y paternalismo; por otra, de carácter administrativo-urbanístico, que podía comprender, en función de la intensidad del estímulo, o bien la segregación de usos no tolerados (zoning), la regeneración y renovación de la ciudad (hausmanización), su ampliación planeada y contigua (ensanche), discontinua (ciudades jardín, siedlungen, casas baratas, ciudad lineal), o modelos equivalentes. 
Con el paso del tiempo, en la segunda mitad del siglo xx la ciudad inicia otro periodo de crecimiento de rasgos similares a los de la centuria anterior -con las lógicas diferencias de escala e intensidad-, del que nuevamente se derivarán múltiples problemas que alimentarán, otra vez, y como cien años antes, la búsqueda de nuevas utopías. Pero una particularidad: a las distopías decimonónicas clásicas, parcialmente asociadas al desorden político-social, se ha ańadido ahora, al comenzar el siglo XXI, el desorden medioambiental, cambio climático e insostenibilidad, científicamente bien documentados (Bulkeley \& Betsill, 2013; Castan \& Bulkeley, 2013; Leichenko, 2011); un desorden trasladado también a la literatura de ciencia ficción o al cine en forma de distopías intuidas, asociadas al fin de la civilización conocida, y en las que se proyecta, en un escenario futuro y catastrófico, los temores del presente. ${ }^{2}$

Junto a ellas, son ya muy evidentes múltiples distopías reales, percibidas, tales como la desigualdad urbana y regional, las migraciones forzadas, las crisis medioambientales, la segregación social, las revueltas sociales, el caos circulatorio o la contaminación ambiental (Davis, 2007). Todas ellas son el germen, el impulso creador, de múltiples estrategias encaminadas a procurar la supervivencia de las ciudades, sin agotar los recursos o causar más dańo al medioambiente; es decir, de forma sostenible.

Dejando al margen la enorme distopía territorial que representa la infraurbanización, es decir, la alta concentración demográfica en territorios sin condiciones de ciudad, y cuya utopía o alternativa es, por el momento, la propia ciudad, las distopías urbanas también son ahora una proyección hacia un futuro catastrófico de las patologías del presente, vinculadas a la hiperurbanización. Toman forma en torno a un conjunto de fenómenos asociados a lo que podemos denominar la ciudad non stop, es decir, la ciudad permanentemente activa todas las horas de todos los días del año; una ciudad -o área urbana- que es una suma de discontinuidades y que progresivamente se confunde con sus patologías, al tratarse de un espacio económica y ecológicamente insostenible.

Vivir en una ciudad se entiende ahora como vivir en un espacio -urban sprawlya indisolublemente unido a los grandes desplazamientos diarios en vehículo privado, a los elevados costes ambientales -residuos sólidos urbanos e industriales, contaminación atmosférica y ruido-, a los nuevos ritmos de vida que impone una extrema zonificación, a la concentración de grandes equipamientos, a la hipertrofia administrativa y procedimental, a la expansión territorial, al extremo e indiscriminado e innecesario consumo de suelo; y también a la especulación inmobiliaria, con todas sus secuelas, como el incremento de los procesos de tugurización, alquileres caros y compartidos, etcétera.

Y como cien años antes, ancladas en estas distopías, se encuentran varias de las nuevas utopías urbanas. Pero con la particularidad de que, frente a la base social y radical de parte de las alternativas decimonónicas -modelo Icaria, New Harmony, 
etcétera-, las utopías del primer cuarto del siglo xxi carecen, en términos generales, de la base filantrópica y pseudopaternalista del pasado; y pueden agruparse, en una primera aproximación y asumiendo un cierto grado de apriorismo, en torno a dos grandes categorías: la utopía urbana como aspiración ideal, posibilista y utilitarista, que imagina un futuro urbano ecoeficiente, sostenido por las nuevas tecnologías de la información; y la necesidad y la inmediatez como impulso utópico que concibe un espacio regenerado, reutilizado-renovado y sostenible de la nueva ciudad (tabla 1). Entre una y otra se dispondrían todas aquellas utopías -en realidad ultrautopías- que, como en el siglo XIX, asociaban la nueva sociedad a nuevas formas de poblamiento antiurbano.

TABLA I | Utopías, escalas y paradigmas en la ciudad del siglo XXI

\begin{tabular}{|c|c|c|c|c|}
\hline \multicolumn{2}{|c|}{ TIPO } & CARÁCTER & ESCALA & PARADIGMA-MODELO \\
\hline \multirow{2}{*}{ 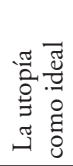 } & A & Tecnológico-posibilista & Toda la ciudad & $\begin{array}{l}\text { Sostenibilidad y smart city: } \\
\text { Masdar City vs. Waterfront Toronto }\end{array}$ \\
\hline & B & Eco-utilitarista & Vivienda, edificio & $\begin{array}{l}\text { Ecoeficiencia y Smart Growth. } \\
\text { NZEB*}^{*} \text {, ecobarrios, ecociudades }\end{array}$ \\
\hline & $\mathrm{C}$ & Ultra utopías & $\begin{array}{l}\text { Lo urbano sin } \\
\text { ciudad }\end{array}$ & Modelo: Free State Project \\
\hline \multirow{2}{*}{ 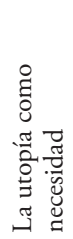 } & $\mathrm{D}$ & $\begin{array}{l}\text { Pragmatismo } 1 \\
\text { Oportunidad inmobiliaria }\end{array}$ & $\begin{array}{l}\text { Edificio, manzana, } \\
\text { barrio }\end{array}$ & $\begin{array}{l}\text { Renovación por desposesión: } \\
\text { sustitución, gentrificación, } \\
\text { recualificación funcional }\end{array}$ \\
\hline & $\mathrm{E}$ & $\begin{array}{l}\text { Pragmatismo } 2 \\
\text { Necesidad, urgencia social }\end{array}$ & Barrio, distrito & $\begin{array}{l}\text { Integración por regeneración: } \\
\text { rehabilitación-regeneración. } \\
\text { La utopía de "protección" }\end{array}$ \\
\hline
\end{tabular}

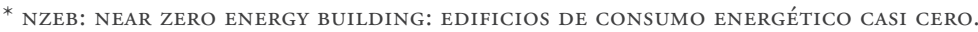

FUENTE ELABORACIÓN PROPIA

Las nuevas utopías urbanas, adscritas a cualquiera de las cinco variantes señaladas, también tienen en común, mutatis mutandis, la propuesta de soluciones locales a los grandes problemas globales, imponiéndose en este proceso nuevos paradigmas como la autogestión, el aprovechamiento de recursos escasos, la revalorización de las comunidades pequeñas (denominadas 'inteligentes'), la recuperación de barrios deteriorados (devastados), el acondicionamiento térmico de la edificación, o incluso las operaciones de renovación selectiva y excluyente (gentrificación). Y es que, con algunas excepciones, salvo en el cine o en la literatura de ciencia ficción, no existen apenas llamamientos y modelos urbanos radicales y alternativos (rupturistas) frente al actual modelo de ciudad, a tal punto que la propia utopía podría considerarse como una forma de distopía (Delgado, 2016).

La primera de ellas, que hemos identificado como utopía tecnológica (A en tabla 1), plantea un futuro en el que los problemas creados por la hiperurbanización del planeta se pueden resolver mediante un aprovechamiento de las posibilidades que ofrece la tecnología, especialmente las tecnologías de la información y la 
comunicación (TIC), para alcanzar el objetivo de la sostenibilidad urbana. Con tal objeto se asume, apriorísticamente, que ambas variables, la inteligencia de la ciudad y la sostenibilidad, están íntimamente asociadas (Deakin, 2014; Fernández Güell, 2015), y que no hay utopía fuera de la ciudad, ya que la ciudad inteligente es la utopía.

Desde esta perspectiva, una ciudad inteligente -smart city- es un espacio con infraestructuras, redes y plataformas inteligentes, con millones de sensores que permiten detectar y comprender lo que está pasando en la ciudad de forma que se pueden tomar las mejores decisiones y proporcionar la información y los servicios adecuados a sus habitantes (Ontiveros, Vizcaíno \& López, 2016). Aunque, al margen de los grandes principios, en la práctica no deja de ser una ciudad que tomará decisiones autónomas a partir de indicadores que permitan resolver los problemas sin intervención humana, y poner remedio con ello, supuestamente, a un crecimiento urbano histórico aparentemente anárquico y distópico.

Obviamente, el carácter utópico de esta propuesta debe ser matizado, ya que, en realidad, en las ciudades inteligentes no se cuestionan los fundamentos últimos y más inestables del sistema, tales como el consumo insostenible de recursos, la huella ecológica u otros, sino que se diseñan soluciones para encauzarlos tecnológicamente con objeto de reducir los impactos del modo de crecimiento urbano tradicional (Fernández, 2015). Buena muestra de esta paradoja es el hecho de que algunas ciudades inteligentes se estén construyendo en los lugares más inhóspitos e insostenibles del planeta, aportando un gran volumen de recursos económicos y, en general, de energía exógena, con la extensión de la huella ecológica que ello comporta.

A nuestro criterio, esta utopía se desarrolla en dos niveles. Un primer nivel, de carácter global, en el que se plantea la construcción de ciudades ex novo, o de partes de ciudad completas y con un tamańo próximo a los 30.000 habitantes, como es el caso de las ciudades de New Songdo, en Corea del Sur, o la ciudad de Masdar City, en Abu Dhabi (Emiratos Árabes Unidos), que se presenta como la primera ciudad totalmente ecológica del mundo, sin emisiones de carbono y sin residuos, o King Abdullah Economic City in Rabigh o incluso el proyecto de la nueva ciudad de Destiny, en Florida, EE.uU. Todas ellas son una buena muestra de las nuevas utopías posibilistas, total o parcialmente futuristas, extremadamente caras, ultracapitalistas, y concebidas como una alternativa radical y tecnológica ante un futuro completamente distópico.

El segundo nivel, de carácter parcial, que identificamos con el proyecto Waterfront Toronto, se corresponde con todas aquellas pequeńas soluciones desarrolladas en ciudades de todas las escalas, aisladas o constituidas en redes de ciudades inteligentes, concebidas para regenerar partes de las mismas o para resolver algunos problemas específicos relacionados con el medioambiente, la movilidad, las formas de gobierno y otros (Villarejo, 2015). Y aunque no existen criterios de reconocimiento global de esta alternativa, algunas grandes regiones, como la Unión Europea, proponen que una ciudad sea considerada inteligente si desarrolla al menos una iniciativa que guarde relación con la economía, la población, el medioambiente, la movilidad y las formas de vida inteligentes (Ontiveros et al., 2016). 
No existen en España iniciativas creadoras de ciudades inteligentes ex novo y sí múltiples iniciativas equivalentes al segundo nivel señalado anteriormente. Gran parte de ellas se canalizan a través de una denominada Red Espańola de Ciudades Inteligentes, constituida en 2012 e integrada por 65 ciudades; ${ }^{3}$ su objetivo no es otro que el de "intercambiar experiencias y trabajar conjuntamente para desarrollar un modelo de gestión sostenible y mejorar la calidad de vida de los ciudadanos, incidiendo en aspectos como el ahorro energético, la movilidad sostenible, la administración electrónica, la atención a las personas o la seguridad". ${ }^{4}$ Se trata esta de una aspiración que viene a confirmar la relativa proximidad entre la utopía urbana como ideal de futuro, y la utopía como necesidad para abordar las distopías medioambientales del presente (Berger, 2014).

La segunda utopía, que hemos denominado eco-utilitarista (B), presenta algunas variantes relacionadas fundamentalmente con la escala de intervención: edificio, barrio, ciudad, nueva ciudad. La primera de ellas está centrada en la mejora de la calidad y sostenibilidad de los edificios, y comprende tanto las obras de mejora de la envolvente térmica del edificio (mejora de su aislamiento térmico, sustitución de carpinterías y acristalamientos, instalación de dispositivos bioclimáticos...), como la instalación de sistemas de calefacción, refrigeración, producción de agua caliente sanitaria y ventilación para el acondicionamiento térmico, o el incremento de la eficiencia energética de los ya existentes, así como la instalación de equipos de generación o que permitan la utilización de energías renovables como la solar, biomasa o geotérmica.

En Europa, este conjunto de acciones está incardinado dentro del ENTRANZE, ${ }^{5}$ que contiene un conjunto de políticas para forzar la transición a los edificios de energía casi nula -NZEB (Near Zero Energy Building)-, mediante una más rápida penetración de estos y la integración de fuentes de energía renovable para calefacción y refrigeración, centrándose en la rehabilitación del parque de edificios existente. Estos objetivos fueron fijados en el contexto de la refundición de la Directiva EPBD (Energy Performance of Buildings Directive, 2010/31/EU) que requiere que todos los nuevos edificios cumplan el con el estándar de NZEB a partir de 2020, y a partir de 2019 en el caso de edificios públicos. ${ }^{6}$

3 Las ciudades que en 2017 integraban esta red eran: A Coruńa, Albacete, Alcalá de Henares, Alcobendas, Alcorcón, Alicante, Almería, Alzira, Aranjuez, Arganda del Rey, Ávila, Badajoz, Barcelona, Burgos, Cáceres, Castellón, Ciudad Real, Córdoba, Guadalajara, El Puerto de Santa María, Elche, Fuengirola, Getafe, Gijón, Jaén, Hospitalet de Llobregat, Huelva, Las Palmas de Gran Canaria, Logroño, Lugo, Huesca, Madrid, Majadahonda, Málaga, Marbella, Mérida, Molina de Segura, Móstoles, Motril, Murcia, Oviedo, Palencia, Palma de Mallorca, Pamplona, Paterna, Ponferrada, Pozuelo de Alarcón, Rivas Vaciamadrid, Sabadell, Salamanca, San Cristóbal de La Laguna, Sant Cugat, Santa Cruz de Tenerife, Santander, Santiago de Compostela, Segovia, Sevilla, Tarragona, Toledo, Torrejón de Ardoz, Torrent, Valencia, Valladolid, Vitoria-Gasteiz y Zaragoza.

4 En http://www.energiamurcia.es/actuaciones/reci

5 Entranze: policies to Enforce the Transition to Nearly Zero Energy buildings in the EU-27. http://www.entranze.eu/

6 Directiva 2010/31/ue del Parlamento Europeo y del Consejo de 19 de mayo de 2010 relativa a la eficiencia energética de los edificios: http://www.gradhermetic.ma/docs/Directiva_2010-13EC_EPBD.pdf 
Uno de los sistemas que se adapta a esta normativa y que está empezando a desarrollarse en algunos países europeos es el estándar PassivHaus, creado en Alemania hace más de dos décadas, con una primera experiencia en Darmstadt, cerca de Frankfurt, que establece métodos, requisitos y sistemas constructivos para alcanzar la eficiencia, y ha de ser certificado oficialmente por el PassivHaus Institut. Hasta 2014 habían sido adaptadas a este sistema de viviendas pasivas o ecoeficientes alrededor de 30.000 viviendas que utilizan diversos recursos de la arquitectura bioclimática; están proyectadas para aprovechar al máximo posible la radiación y la luz solar, manteniendo en invierno el calor recibido de esta fuente, el calor generado por los propios usuarios y el que producen los diferentes aparatos electrodomésticos.

La segunda variante de esta utopía, cercana al modelo del llamado crecimiento inteligente -smart growth- intentó, en origen, combatir los efectos negativos del suburbio de baja densidad, especialmente la dispersión de las zonas residenciales, el consumo de suelos agrícolas y naturales, la polución atmosférica, y la oferta de vivienda que beneficiaba a los grandes lotes periféricos (Gavinha \& Sui, 2003). Este modelo caracterizó a no pocas propuestas correctoras en la ciudad de EE.UU., y en alguna medida inspiró el espíritu participativo y colaborador de algunas nuevas formas de urbanización autosuficientes -es decir, sostenibles-, de las que son modélicos algunos proyectos como el denominado ReGen Villages, desarrollado en la ciudad de Almere, Países Bajos.

En una escala similar se encuentran los denominados ecobarrios -e incluso las nuevas ecociudades-, es decir, aquellos espacios urbanos de nueva construcción o regenerados a partir de principios de sostenibilidad y cambio en los hábitos de vida de la población, en los que se reduce el impacto medioambiental merced al desarrollo de procesos ecoeficientes vinculados al ciclo del agua, ahorro en energía y materiales, mejora del entorno vegetal y la biodiversidad, en los que se procura una buena comunicación con el resto de la ciudad mediante transporte público eficiente.

Los ejemplos de esta alternativa urbana son ya numerosos, destacando, entre los pioneros, el barrio de Vauban, situado al sur de la ciudad de Friburgo (Alemania), el barrio de BedZed en Londres, el Hammarby Stjöstad en Estocolmo, o el Niewland Amersfoot en Holanda, y diversos proyectos de ecobarriadas en Bogotá, Santiago de Chile o Coyoacán en Ciudad de México. En Espańa se han desarrollado y planificado múltiples iniciativas orientadas tanto a la construcción ex novo de barrios sostenibles -Santa Bárbara en Sevilla, Valdespartera en Zaragoza o Vallbona en Barcelona- como a la regeneración de barrios vulnerables como el de Puente de Vallecas en Madrid, en que se ensaya una variante radical del modelo, habitual en la resolución de graves problemas de vulnerabilidad urbana: realojo de los habitantes, planificación y urbanización del nuevo barrio de acuerdo a criterios de calidad y sostenibilidad, demolición y construcción de los nuevos edificios y creación de servicios colectivos. En otros casos, en cambio, como el del Polígono de Santa María en Toledo, o el Cuatro de Marzo en Valladolid, se mantiene la edificación original para reformarla mediante intervenciones tendentes a mejorar la eficiencia climática de los edificios. ${ }^{7}$

7 El barrio del Cuatro de Marzo de Valladolid forma parte de la iniciativa europea R2CITIES, junto a las ciudades de Génova (Italia) y Kartal-Estambul (Turquía). En ellas se diseñarán, construirán 
Finalmente, diferenciamos una tercera vía hacia la utopía, que denominamos ultrautopía (C), ya que comprende algunas iniciativas extemporáneas, en cierto modo cercanas a la utopía comunista del movimiento icariano, impulsado por Etienne Cabet a mediados del siglo XIx. Se trata tanto del denominado Free State Proyect, un movimiento etiquetado como libertarismo o liberalismo libertario, pseudoanarquista, aparentemente próximo al viejo movimiento hippie iniciado en EE.Uu. en 2001, con el objetivo de crear un Estado libre dentro del Estado de New Hampshire (Fernández, 2013). Y también, aunque sea parcialmente, del movimiento de ecoaldeas, con el que se quiere reproducir no solo la vuelta a la naturaleza, sino también viejas formas de vida autosuficientes, alternativas y alejadas de cualquier entorno urbano. En España este movimiento está encauzado a través de la denominada Red Ibérica de Ecoaldeas, fundada en 2001 con el objetivo de difundir el concepto de ecoaldea y asentamiento sostenible, y "facilitar el acercamiento de las personas que, desde pueblos y ciudades, desean apostar por estas formas de vida" ${ }^{\text {. }}$

Estas alternativas ultrautópicas, concebidas para responder a discrepancias político-filosóficas o aspiraciones individuales sobre la relación con la naturaleza, aparecen maximizadas y convertidas en tópico, en la literatura y cultura distópico-utópica, como entidades creadas espontáneamente para afrontar grandes cataclismos, agotamiento de recursos, crisis medioambientales, conflictos bélicos, lucha por recursos escasos -agua, energía-, u otros; tienen como fundamento la huida y la búsqueda de soluciones que exaltan lo pequeño, la autogestión, la voluntaria reclusión en comunidades cerradas, habitualmente en conflicto permanente con otras comunidades o grupos también pequeños -así sucede en las utopías de ficción-, ante la posibilidad de que sean portadoras de cualquier amenaza para el grupo.

No existen en España iniciativas relevantes de la entidad e ideología señaladas. Las respuestas a la problemática urbano-territorial de la segunda década del siglo XXI no podían aspirar a reproducir este u otros modelos equivalentes, más o menos utópicos; y es que, nada en la ciudad espańola puede evitar la muy estricta regulación urbanística, el laberinto normativo -planes, ordenanzas, jurisprudencia, fiscalidad- en la que tiene que sobrevivir cualquier iniciativa territorial; y tampoco al estricto marco regulador impuesto por la UE y por los gobiernos regionales, obligados a someter al conjunto del sistema a políticas de renovación y regeneración, etiquetadas como sostenibles.

Aunque en sentido estricto, solo estas últimas, impulsadas por las administraciones públicas y combinadas con una severa restricción al crecimiento territorial expansivo, conforman el ideario de la nueva y pragmática utopía urbana: construir sobre lo ya construido. En unos casos (tipo D en la tabla 1), explotando la oportunidad inmobiliaria para proceder a una calculada renovación por desposesión, en la que se sustituyen inmuebles, clases sociales y actividades; y, en otros casos (tipo E), dando solución a la necesidad y urgencia social concentrada en múltiples barrios vulnerables, para proceder a una suerte de integración protegida mediante programas de regeneración urbana integral.

y gestionarán proyectos de renovación y rehabilitación de edificios a gran escala, con el objetivo de conseguir progresivamente barrios y ciudades de consumo energético casi nulo. 
Y es que la sostenibilidad, renovación y regeneración como atributos del nuevo paradigma social-urbano, integran lo que hemos denominado pragmatismo urbanístico, es decir, del fin de la utopía social y urbanística, reducida ahora a cuestiones relacionadas con las denominadas soluciones inteligentes impulsadas por la necesidad ante un futuro medioambientalmente comprometido e incierto. De la ciudad social y urbanísticamente utópica, se ha pasado al más descarnado y necesario pragmatismo o posibilismo autocontenido: menor consumo de suelo, de energía, y de recursos.

\section{Renovación y regeneración: una aproximación al pragmatismo utópico en la ciudad española del siglo XXI}

La crisis económica e inmobiliaria del final de la primera década del siglo xxi, hizo aflorar en la ciudad española múltiples indicadores de malestar-distopías-, en el modelo de ciudad de los múltiples excesos inmobiliarios, dando por concluida la etapa de llenado de la periferia y vaciado del centro (Calderón \& García, 2005); una etapa de absoluta subordinación del crecimiento urbano a las estrategias del mercado inmobiliario (Calderón, 2002), que sirvió para ańadir a la ciudad nuevas urbanizaciones residenciales absolutamente insostenibles desde la perspectiva económica y medioambiental (Calderón, 2004). Consecuentemente, y tras constatar la entidad del despilfarro de la primera década del siglo xxI, se acabó por imponer en toda Europa, y de forma singular en España, un radical cambio de paradigma en favor de un crecimiento más sostenible, materializado con intensidad variable en las que podemos denominar utopías pragmáticas -en realidad, falsas utopías-, las cuales transmutan el desorden distópico de la ciudad poscrisis de la segunda década del siglo XXI en un nuevo orden, impulsado tanto por el sector inmobiliario empresarial como por el sector público-social (Calderón \& García, 2017).

Para desarrollar este nuevo paradigma (véase tabla 2), se utilizaron básicamente tres instrumentos: la Ley 8/2007, de 28 de mayo, de Suelo; el Real Decreto 233/2013, de 5 de abril, por el que se regula el Plan Estatal de fomento del alquiler de viviendas, la rehabilitación edificatoria y la regeneración y renovación urbanas 2013-2016; y la Ley 8/2013, de 26 de junio, de rehabilitación, regeneración y renovación urbanas. En ellos se diseña una nueva estrategia de recuperación económica, apoyada en la reconversión del sector inmobiliario y de la construcción, para impulsar un modelo urbano sostenible e integrador desde el punto de vista ambiental, social y económico; esta estrategia parte de la constatación de la entidad del despilfarro de la primera década del siglo xxi, ya que, según el Sistema de Información Urbana y el Estudio de Sectores Residenciales en España 2011, ambos elaborados por el Ministerio de Fomento, Espańa poseía suelo calificado capaz de acoger nuevos crecimientos urbanísticos para los próximos cuarenta y cinco años y un stock de 723.043 viviendas nuevas vacías. 
TABLA 2 Un modelo de desarrollo urbano sometido a la sucesión de paradigmas antagónicos (crecimiento indefinido versus sostenibilidad)

\begin{tabular}{|l|l|l|}
\hline Período & $\begin{array}{l}\text { Inicio y final de trayectoria expansiva: } \\
1998-2007\end{array}$ & $\begin{array}{l}\text { Inicio y trayectoria de retorno 2008- } \\
2017\end{array}$ \\
\hline Paradigma & $\begin{array}{l}\text { Gestión indiscriminada de la escasez: } \\
\text { boom inmobiliario }\end{array}$ & Gestión selectiva de la escasez \\
\hline Legislación & $\begin{array}{l}\text { Ley 6/1998, de 13 de abril, sobre } \\
\text { Régimen del Suelo y Valoraciones }\end{array}$ & $\begin{array}{l}\text { Ley 8/2013, de 26 de junio, de Rehabi- } \\
\text { litación, Regeneración y Renovación }\end{array}$ \\
\hline Utopía dominante & Inmobiliaria & Sostenibilidad \\
\hline Efectos & Crecimiento de las periferias & Contención crecimiento espacial \\
\hline Tipo de crecimiento & Descentralización concentrada & Renovación y regeneración selectivas \\
\hline Modelo de ciudad & La ciudad “periferia” & $\begin{array}{l}\text { Vuelta a los orígenes: la ciudad de la } \\
\text { memoria }\end{array}$ \\
\hline Distopías & Ciudad non stop & La ciudad inaccesible \\
\hline
\end{tabular}

Particular importancia tendrá, en este inevitable y necesario cambio de estrategia, el Real Decreto 233/2013, de 5 de abril, citado anteriormente, ya que representa un cambio en la política de vivienda en España. En efecto, desde 1981 la intervención estatal en el mercado de la vivienda se materializó en diez planes, de los que los nueve primeros (1981 a 2012) compartían tres características básicas: fomentaban la producción de un volumen creciente de viviendas, alentaban la ocupación de nuevos suelos y el crecimiento de las ciudades, y finalmente priorizaban la propiedad como forma esencial de acceso a la vivienda. ${ }^{9}$ En cambio, el último de los planes (2013-2016) introdujo un cambio sustancial en las formas de intervención en la ciudad, de trascendencia notable para el entonces deprimido mercado de vivienda en España: en él se fomenta la rehabilitación, renovación y regeneración mediante un jerarquizado sistema de ayudas que permite derivar la estrategia del capital promotor-constructor, una vez más, hacia la ciudad consolidada.

Con la mencionada legislación se pone fin al hipercrecimiento urbano para sustituirlo por pequeñas intervenciones en la ciudad, con las que se materializan las dos pseudoutopías citadas: la regeneración o -lo que es lo mismo- la recuperación de funciones perdidas o deterioradas, ya que con ella se da nuevo ser a algo que degeneró, para restablecerlo o mejorarlo, materializando con ello la utopía de la ciudad sostenible; y la renovación, que implica sustituir una cosa vieja, o que ya ha servido, por otra nueva de la misma clase, y que habitualmente es falsa renovación, ya que lo nuevo, en la reconstrucción de la ciudad, rara vez es de la misma clase, tipología de ocupación y uso que sustituye.

9 Los planes de vivienda en España en el período 1981-2016 fueron: 1981-1983 (R.D. 2455/1980), 1984-1987, (R.D. 3280/1983), 1988-1992 (R.D. 1494/1987), 1992-1995 (R.D. 1932/1991), 1996-1999 (R.D. 2190/1995), 1998-2001 (R.D. 1186/1998), 2002-2005 (R.D. 1/2002), 2005 2008 (R.D. 801/2005), 2009-2012 (R.D. 2066/2008), 2013-2016 (R.D. 233/2013). 
La renovación por desposesión como nueva estrategia inmobiliaria:

de la ciudad-periferia a la nueva ciudad-centro

Una de las respuestas al hipercrecimiento urbano y patologías a él asociadas está vinculada al nuevo paradigma que introduce la Ley 8/2013 de Rehabilitación, Regeneración y Renovación urbanas (tabla 2). El objetivo declarado en ella no es otro que contribuir activamente a la sostenibilidad ambiental, a la cohesión social y a la mejora de la calidad de vida de todos los ciudadanos, tanto en las viviendas y en los edificios como en los espacios urbanos; pero es también una respuesta al agotamiento del modelo de negocio de la construcción de vivienda nueva en las periferias, dado que posibilita nuevos escenarios de actividad en la ciudad consolidada, ya sea para la rehabilitación o regeneración integradas o para la renovación, es decir, para la creación de nuevos contenedores urbanos -como se venía haciendo desde finales del siglo $\mathrm{xx}$-, previa desposesión de los valores del lugar, sustituyendo no solo el viejo caserío, sino también su población y usos en los muy terciarizados centros urbanos.

Tras la crisis económica de la primera década del siglo xxI, la nueva estrategia inmobiliaria consiste en abandonar las grandes promociones residenciales ultraperiféricas y sustituirlas por promociones de carácter más pequeño en el interior de la ciudad, ubicadas en algunos lugares estratégicos. En todas ellas se vuelve a poner en valor la localización frente a la aglomeración residencial pseudourbana de las periferias, colmatando, es decir, ocupando intensivamente, los escasos poros -suelo sin edificar- por los que todavía respiraba la ciudad compacta. De este modo, a la clásica gentrificación se añade una renovación completa de carácter funcional, ya que lo que se altera, de forma radical, es el perfil de todas las actividades y funciones tradicionales, en lugares de elevada centralidad, sometidos a una estricta selección estratégico-empresarial.

Frente a las grandes operaciones de renovación del último tercio del siglo xx, como la ejecutada en el entorno del río Manzanares en Madrid, o la renovación de la Ría de Bilbao, impulsadas por el sector público, las operaciones de renovación del siglo Xxi son por lo general de escala menor -manzana, edificio-, y en ellas no se reconoce el valor de las preexistencias; son lideradas por el sector privado, tienen un carácter muy selectivo y no responden a un agotamiento extremo de las condiciones de uso de la edificación, equipamientos o infraestructuras.

Este modus operandi responde, en parte, al conocido fenómeno de vuelta al centro, es decir, a una no declarada operación de renovación que se lleva a cabo tras desposeer a un lugar de sus valores originales, y que presenta dos variantes. Una de ellas está vinculada a los procesos de gentrificación, resaltando el carácter dual de sus resultados, ya que las operaciones no pueden impedir que coexistan áreas renovadas y áreas sometidas a procesos de tugurización, como sucede, por ejemplo, en el caso de Barcelona con el barrio del Raval. En la otra variante se asume la quiebra del modelo de ciudad inherente al centro urbano, puesta de manifiesto en la pérdida de las funciones tradicionales -industria o residencia-, y se plantea su reemplazo por otras con mayor necesidad de centralidad, aprovechando las oportunidades que abrieron en su día algunos instrumentos de teórica protección, como fueron los Catálogos de los Planes Generales de Ordenación Urbana (Álvarez Mora, 2015 y 2016). 
La dinámica renovadora, que consiste en remudar, poner de nuevo o reemplazar algo, es consustancial a la ciudad de comienzos del siglo xxi y ha requerido de un soporte legal de asimilación entusiasta y acrítica, tras los excesos del boom inmobiliario. Tal dinámica se ha visto acompañada de un fuerte incremento de los precios del suelo del centro urbano y de un cambio en su perfil funcional, al dar cabida a una nueva generación de usos terciarios necesitados de centralidad, que operan conforme a la estrategia de tierra quemada, es decir, ocupando y arrasando todo vestigio de uso tradicional. De este modo, en lo sucesivo y en ese lugar, solo tendrá cabida esa actividad u otras equivalentes, siempre que estén adaptadas a la funcionalidad y precio de los nuevos contenedores que se van construyendo o remodelando.

El objetivo de estas operaciones no es erradicar la pobreza, sanear o esponjar urbanísticamente el centro, como se hace en el centro de Barcelona (Tapada-Berteliy \& Arbaci, 2011), sino insertar nuevas actividades generadoras de riqueza explotando la centralidad y las nuevas pautas de consumo y ocio social, como se pone de manifiesto en las grandes operaciones de escala metropolitana ya ejecutadas (Bilbao Ría 2000) o en ejecución (Mahou-Calderón). Se trata de una operación concebida como una auténtica reconversión inmobiliaria que transformará siete grandes edificios del centro de Madrid, junto a la Puerta del Sol, que habían albergado las sedes de entidades financieras como Banesto, Central Hispano y Zaragozano, convirtiéndolos en un hotel y apartotel gestionados por la cadena Four Seasons, y un centro comercial de alto nivel (Ávila et al., 2016). Esta obra, ya en ejecución, fue paralizada por el Consistorio y el Juzgado, entre otros motivos, por el derribo no autorizado de elementos protegidos. Las obras se reanudaron, a finales de 2015, tras la posterior resolución judicial y la negociación entre administración y promotores, que supuso la reducción de la edificabilidad y la supresión de la estación subterránea de autobuses. La renovación de esta gran manzana, próxima a la Puerta del Sol y todavía inconclusa en la primavera de 2017, ya ha generado una dinámica transformadora en todo su entorno, influyendo en una notable reconversión de la oferta hotelera y, confirmando, una vez más, el valor estratégico de algunas operaciones inmobiliarias importantes en el centro de las grandes ciudades. De forma aparentemente contradictoria, en este proceso de destrucción deliberada y selectiva de la ciudad ha podido resultar determinante toda la estrategia conservacionista, protectora, vinculada a la legislación sobre el suelo o sobre el patrimonio histórico (Álvarez Mora, 2016). Y es que la identificación de los elementos susceptibles de proteger facilitaba la intervención en el resto del patrimonio edificado, de forma que es habitual que coincidan durante algún tiempo dos grandes vacíos: los edificios vacíos catalogados -de intervención compleja y costosa-, y solares vacíos, recalificados para dar cabida a los nuevos usos urbanos llamados a ocupar los huecos que generaban, por exclusión, los fragmentos -edificios- de la ciudad catalogada.

\section{Regenerar como alternativa al optimismo urbanizador en la ciudad española del siglo xxI}

Una segunda alternativa, esencialmente pragmática a la distopía sociourbanística, se esconde bajo el impulso regenerador que lideran las administraciones públicas, concebido para prolongar la vida útil de sectores de la ciudad social y urbanísticamente 
muy degradados. Se trata de barrios de urbanización marginal y polígonos de vivienda oficial de los ańos cincuenta a setenta, con un atormentado horizonte distópico del que son indicadores avanzados el deterioro del paisaje urbano y la vulnerabilidad residencial. Esta nueva utopía —en realidad una nueva utopía de protección oficial—, según la cual el tejido urbano es reutilizable sin mutar sustancialmente su perfil social y funcional, está revestida del transversal paradigma de la sostenibilidad y requiere de una poderosa y sostenida inversión pública (Gaja, 2015b). Es que, ante la imposibilidad de que sean los empobrecidos vecindarios los que tomen la iniciativa y asuman los costes, es la administración el único agente que puede corregir los problemas urbanísticos y edificatorios de los grandes barrios de la ciudad de la segunda mitad del siglo xx (Ruiz, 2015).

FIGURA 2 | Localización de las ciudades con barrios vulnerables en España, 2011

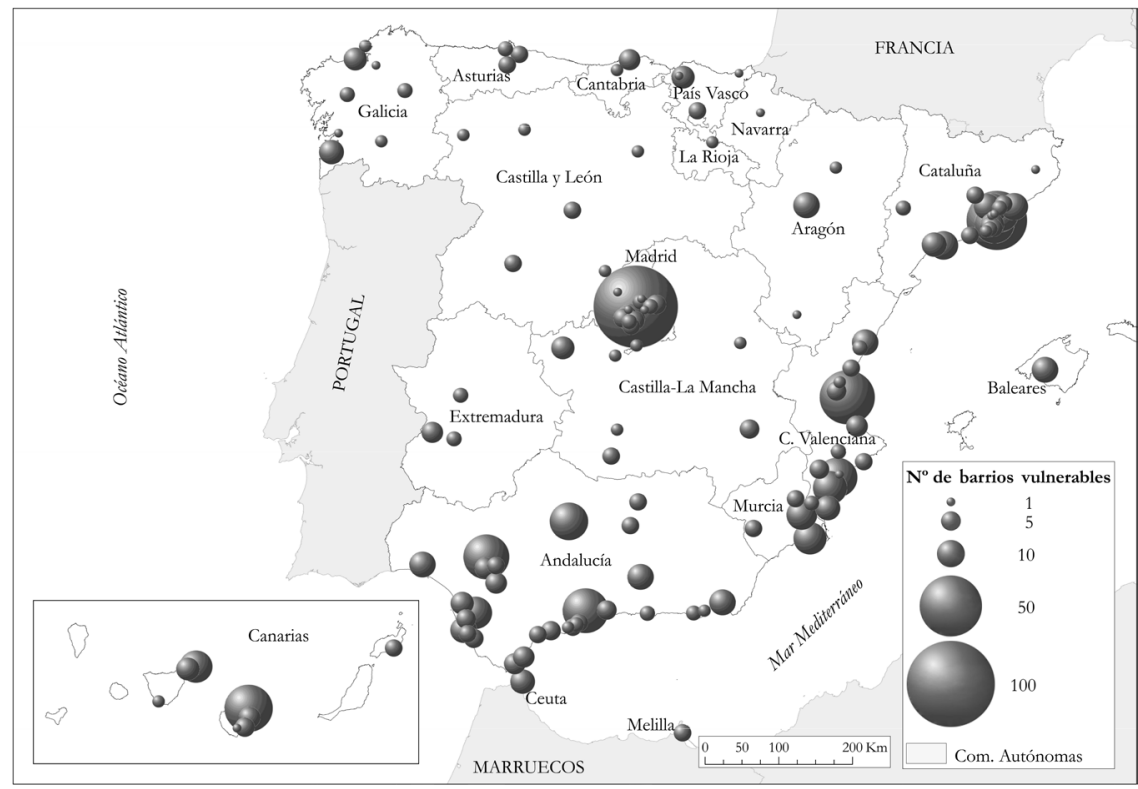

FUENTE ELABORACIÓN PROPIA A PARTIR DE HTTPS://WWW.FOMENTO.GOB.ES/

Y el problema era ciertamente preocupante: en 2011 existía en las ciudades espańolas un total de 918 barrios vulnerables, de los que diez se encontraban en situación de vulnerabilidad muy alta y, por lo tanto, necesitados de una intervención remedial y urgente, ya que en su mayor parte correspondían a barrios de urbanización marginal. ${ }^{10}$ En el resto de los barrios con situaciones de vulnerabilidad alta (33), media (392) o baja (483), era notable el porcentaje de viviendas en edificios

10 Los diez barrios de muy alta vulnerabilidad en 2011 eran: Virgen del Remedio I-II (Alicante), El Palmeral-Sant Antoni (Elche), El Puche (Almería), Centro Oeste-Carretera de La Mojonera (Roquetas de Mar), Príncipe (Ceuta), Cruz de Piedra-Sansofé (Las Palmas), Salud Alto (Santa Cruz de Tenerife), Las Vegas (Sevilla) y Los Pájaros (Sevilla). http://www.fomento.gob.es/MFOM. BarriosVulnerables/ 
con un estado de conservación ruinoso, malo o deficiente. La media de este indicador en Espańa, en 2011, era del 6,99\%, pero en gran parte de estos barrios se superaba con creces el $17,4 \%$, que es el umbral de vulnerabilidad establecido por el Atlas de Vulnerabilidad Urbana para este criterio. ${ }^{11}$

En este conjunto de barrios vulnerables es donde se concentraba, en 2011, el grueso del denominado parque de viviendas "de intervención prioritaria" (Ministerio de Fomento, 2014). Las carencias más relevantes detectadas en él eran las de accesibilidad y estado de conservación; en 2011 existían 3,4 millones de viviendas con cuatro plantas o más y sin ascensor, y 1,8 millones de viviendas cuyo estado de conservación era ruinoso, malo o deficiente, lo que suponía el 13,5\% y el 7\% del parque familiar, respectivamente. En cambio, los indicadores de vulnerabilidad extremos, vinculados a las formas residuales de infravivienda -viviendas sin inodoros, sin agua, sin baño o ducha, o sin evacuación de aguas residuales-, que se concentraban en viviendas secundarias o vacías ubicadas en municipios pequeńos, apenas representaban el $1 \%$.

La respuesta dada a estos problemas consiste en regenerar, mediante un programa amparado por la administración, las históricas y mal integradas áreas de urbanización marginal, y especialmente los grandes barrios de vivienda oficial (polígonos) de los ańos sesenta (Rubio \& Molina, 2010), de baja calidad constructiva, afectados por una notable pérdida de valor patrimonial y por un proceso de tugurización y vulnerabilidad tan relevante, que hace necesaria una elevada inversión para renovar todas sus infraestructuras, edificios y equipamientos; un problema especialmente grave si se considera que estos barrios conforman el grueso del tejido residencial de la ciudad compacta en España (Campesino, 2014). Según el Censo de Vivienda del ańo 2011, el 23,1\% del parque edificado de viviendas principales en España se construyó entre 1951 y 1970 , que si se suma al construido entre 1971 y 1980 (el $21,1 \%$ ), aportan casi el $45 \%$ del tejido edificado, total o parcialmente en polígono, por iniciativa pública o privada, en la ciudad espańola.

Esta suerte de reutilización de la "ciudad polígono", en forma de nuevo crecimiento interior, trataría de corregir la obsolescencia urbana, entendida como un factor "derivado de la inusitada velocidad con la que se producen los cambios económicos y tecnológicos en el tardocapitalismo" (García \& Valero, 2016), posibilitando con ello una prolongación del ciclo de vida útil de la edificación, sistemáticamente deteriorada, y de los barrios en los que se emplaza (Castrillo, 2010). Se trata de operaciones muy costosas, cuyo desarrollo y conclusión es imposible de anticipar, y con las que se quiere poner orden a la distopía sociourbanística, aplicando, con este objetivo, un modo de intervención remedial y pragmático, revestido del omnicomprensivo paradigma de la sostenibilidad, que constituye el horizonte utópico para el gobierno de la ciudad en el futuro.

Por lo general se trata de operaciones que requieren de la participación económica de la población residente, y que suceden a las llevadas a cabo en los centros históricos en los años ochenta y noventa del siglo xx, amparadas bajo las denominadas Áreas de Rehabilitación Integral o figuras de planeamiento equivalentes 
(Manero, 2009; Rubio del Val, 2011). Tienen la particularidad, sin embargo, de que a los objetivos tradicionales de tales operaciones, como la habitabilidad, la inclusión social o la competitividad, se añaden, desde principios del siglo XXI, otras variables vinculadas a la calidad medioambiental y especialmente la sostenibilidad; un objetivo que conecta estas actuaciones locales, necesarias y pragmáticas, con la utopía global urbana equivalente: diseńar ciudades para un pequeño planeta (Rogers, 2000).

Este cambio de ciclo tiene como antecedente algunas iniciativas regionales innovadoras, como la Ley de Barrios de Cataluña (2004), o la Ley de Rehabilitación de Barrios de Baleares (2009), y se apoya en la Ley 8/2013, de 26 de junio, de Rehabilitación, Regeneración y Renovación, y en un primer Real Decreto 233/2013, de 5 de abril, por el que se regula el Plan Estatal de fomento del alquiler de viviendas, la rehabilitación edificatoria, y la regeneración y renovación urbanas 2013-2016. Este plan, dotado con una financiación de 2.311 millones de euros, tenía por objeto facilitar el acceso a la vivienda a los sectores de población con menos recursos y apoyar el alquiler como vía idónea para el acceso a la vivienda, especialmente para quienes disponen de menores niveles de renta, así como para dar salida al stock de vivienda vacía acumulada como consecuencia de la crisis inmobiliaria de 2007. Además de estas dos líneas maestras, y con objeto de mejorar los tejidos residenciales y recuperar funcionalmente conjuntos históricos, centros urbanos, barrios degradados y núcleos rurales, el plan impulsaba la realización conjunta de obras de rehabilitación de edificios y viviendas, de urbanización o reurbanización de espacios públicos y, en su caso, dotación de equipamientos en sustitución de edificios de viviendas.

La inversión realizada entre 2013 y 2016 con objeto de rehabilitar y regenerar las viviendas anteriores a 1981, ascendió a 2.527 millones de euros, de los que 2.311 correspondieron al Ministerio de Fomento y 216 a los gobiernos de las Comunidades Autónomas; y si se añaden los 1.268 millones de inversión privada inducida, el programa ha representado a su término una inversión total de 3.755 millones de euros, que han permitido conceder 200.000 ayudas al alquiler, rehabilitar 50.000 viviendas y conceder 230.000 ayudas de subsidiación de préstamos hipotecarios. De este modo, los edificios y viviendas de protección oficial en origen, concebidos para materializar la utopía de la propiedad como forma de acceso a la vivienda en España, vuelven a ser, medio siglo después, el centro de una nueva utopía protegida, relacionada ahora con la sostenibilidad, para cuya materialización se emplean dos grandes instrumentos: la rehabilitación y la regeneración.

La evolución del número de licencias de edificación concedidas en España según el tipo de obra - nueva o rehabilitación- viene a confirmar la nueva estrategia de intervención en la ciudad española, ya que, como se aprecia en la figura 3, desde el año 2012 es siempre mayor el número de licencias que se conceden para rehabilitar, que las que se conceden para realizar obra nueva. Es cierto que la estadística es en cierto modo engañosa, ya que bajo la licencia de rehabilitación pueden quedar comprendidas obras de muy diversa entidad, tales como ampliación, vaciado, cimentación, cubiertas, fachadas, etcétera, pero ello no empaña los resultados del nuevo paradigma, puesto de manifiesto de forma indirecta en la sostenida caída de las licencias de obra nueva que se advierte en España desde el año 2007. 
FIGURA 3 | Número de licencias de construcción por año, según tipo de obra: nueva o rehabilitación. España, 2005-2015

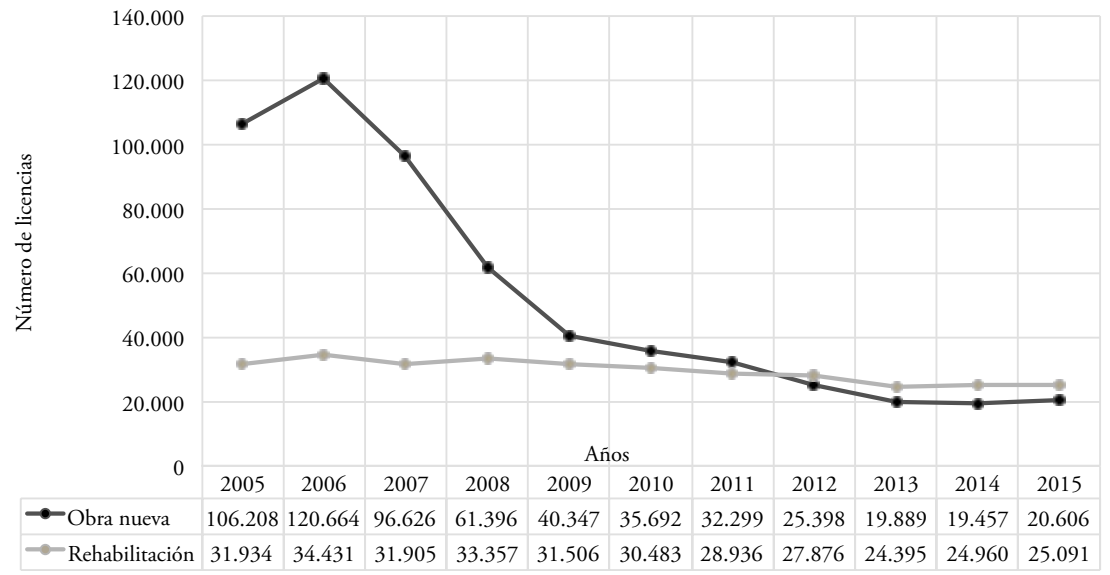

FUENTE ELABORACIÓN PROPIA A PARTIR DE HTTP://WWW.FOMENTO.GOB.ES/BE/?NIVEL=2\&ORDEN= I 0000000

Los ejemplos de esta estrategia, impulsados por los gobiernos municipales y regionales -en España, las Comunidades Autónomas- son muy numerosos, si bien son diferentes las figuras legales que regulan las ayudas a los distintos proyectos, y obviamente la escala de la intervención, ya que puede afectar a conjuntos relativamente extensos, como los cascos históricos, o a ámbitos de escala menor. Los barrios intervenidos con este y otros programas anteriores son muy numerosos, destacando los de Juan Xxiır en Alicante, Trinitat Nova en Barcelona, Rondilla en Valladolid, el Picarral en Zaragoza, Ciudad de los Ángeles, la Unidad Vecinal de Absorción (UvA) de Hortaleza, la "Colonia Experimental de Villaverde" en la ciudad de Madrid, o el barrio de los Rosales en Murcia. Resulta especialmente relevante -por su entidad y coherencia- la actuación en veinte barrios llevada a cabo en Andalucía entre 2015 y 2017, ya que le ha permitido regenerar áreas especialmente vulnerables desde la perspectiva urbanística y social. ${ }^{12}$

Finalizado el Plan Estatal 2013-2016 de Fomento del Alquiler de Viviendas, la Rehabilitación Edificatoria, y la Regeneración y Renovación Urbanas, se han empezado ya a apreciar en la ciudad espańola, en 2017, algunos cambios de estrategia por parte de la promoción inmobiliaria, que pueden anticipar un futuro cambio de paradigma, es decir, el inicio de otro nuevo ciclo urbano.

12 Los barrios intervenidos fueron: Barriada La Chanca en Almería, Barriada La Paz en Cádiz, Barrio Alto y Barrio Bajo de Sanlúcar de Barrameda (Cádiz), Barriada Las Palmeras-Electromecánica en Córdoba, Tercera fase UE-3 subfase 1 (UE 1.3.1) y parte subfase 2 (UE 1.3.2) PERI ATM-2 Santa Adela de Granada, Barriada Huerta Carrasco-Esparraguera en Motril (Granada), Barriada de Arrayanes en Linares (Jaén), Barriada El Rancho en Morón de la Frontera (Sevilla), Barriada Esperanza-La Fuentecica en Almería, Barriada Antonio Muro en Puerto Real (Cádiz), Barriada Polígono Santa María del Valle en Jaén, Barriada Trinidad Este-Perchel Norte en Málaga y Barrio de Veracruz en Antequera (Málaga). 
A este cambio de estrategia se pueden asociar ya algunos indicadores, como son, en primer lugar, la reorganización del sector de la promoción inmobiliaria por fusiones y adquisiciones de empresas y el incremento del precio de los alquileres en las grandes ciudades como Madrid y Barcelona, como resultado de la revalorización de las localizaciones más accesibles -centro y barrios de su primera periferia decimonónica. El mismo carácter tiene la mayor competencia por el escaso suelo clasificado como urbano sin edificar en algunas ciudades, reactivando las tradicionales tensiones especulativas, así como que empiece a ser común que las nuevas promociones se vuelvan a vender sobre plano, lo que es un indicador, sin duda, de la mayor presión de la demanda de vivienda nueva en Espańa al comenzar el año 2017, tras una década completa de crisis del sector de la promoción y cambio de legislación urbanística.

\section{Conclusión}

La investigación que respalda a este texto, y la reflexión que de ella se deriva, nos permiten confirmar que hay períodos en la historia de la ciudad en que los problemas urbanos y las estrategias políticas para afrontar su solución provocan un cambio más o menos radical -teórico y práctico- del modelo de urbanización. Y que estos fenómenos de distopías y rupturas, y de cambios de paradigma en la búsqueda de alguna utopía, han coincidido, en la historia contemporánea de la ciudad, con los dos últimos períodos interseculares; es decir, en el tránsito del siglo XIX al $\mathrm{xx}$, y de este al siglo xxI.

Conocidas y muy bien documentadas las distopías y utopías del primer periodo, hemos tratado de demostrar, tomando como referencia la ciudad española, que en este segundo gran período intersecular -siglo xx al XXI-, se están reproduciendo, mutatis mutandis, algunos fenómenos equiparables; todas las alternativas a los problemas de la ciudad -salvo excepciones- se materializan ahora en la misma ciudad; en cierto modo, es ahora la ciudad el espacio por descubrir y reutilizar, dado que ya no es factible la creación de grandes nuevas ciudades de reemplazo, o su ampliación indefinida, sino redescubrir y reutilizar el territorio de la propia ciudad.

Se ha constatado, asimismo, que ahora, en los albores del siglo xxI, el objetivo consiste no tanto en promover utopías imposibles -ultrautopías-, sino en recrear utopías posibles -ecoutopías- a escala media o pequeña, o bien desarrollar el necesario pragmatismo inmobiliario-residencial que transforme, morfológicamente, el centro de las ciudades, desplegando un implacable mecanismo de renovación por desposesión. Y de forma complementaria, aplicar un nuevo pragmatismo social, vinculado al proceso de regeneración, con el que se tratan de corregir los errores de los periodos de hipercrecimiento urbano de la segunda mitad del siglo xx. Pero con una particularidad: el desorden político-social que alentó el cambio en el primer periodo intersecular, se ha transformado ahora, cien años después, en desorden medioambiental, que se trata de corregir mediante políticas -en la práctica, inversiones públicas- que permitan sobrevivir a las ciudades durante largo tiempo sin necesidad de ampliar desproporcionadamente su perímetro, y sin agotar los recursos o causar grave dańo al medioambiente. Es decir, de forma sostenible. 


\section{Referencias bibliográficas}

Ávila, D., García, B., García, S., García, E., Muñoz, Ó. \& Parajuá, D. (Observatorio Metropolitano) (2016). Órdenes urbanos: centros y periferias en el Madrid neoliberal. En Grupo de Estudios Antropológicos La Corrala (coord.), Cartografía de la ciudad capitalista. Transformación urbana y conflicto social en el Estado Español (pp. 161-194). Madrid: Traficantes de Sueños. https://www.traficantes.net/sites/default/files/pdfs/ cartografia_web_2_0.pdf

Álvarez Mora, A. (2015). La ciudad como producto versus la ciudad como obra, o la realidad urbana entre el espacio de la renta y el espacio social. Valladolid: Universidad de Valladolid.

Álvarez Mora, A. (2016). Las prácticas de la conservación patrimonial como inductoras de la degradación, el abandono y la ruina. En F. Manero Miguel \& J. L. García Cuesta (coords.), Patrimonio cultural y desarrollo territorial - Cultural Heritage \& Territorial Development (pp. 159-189). Navarra: Thomson Reuters-Aranzadi. http://uvadoc.uva. es/handle/10324/24331

Benevolo, L. (1976 [1963]). Origenes del urbanismo moderno. Madrid: H. Blume.

Berger, M. (2014). The unsustainable city. Sustainability, 6(1), 365-374. http://dx.doi. org/10.3390/su6010365

Brandis, D. (2012). Los grandes desarrollos residenciales de la periferia de Madrid: de la burbuja a la crisis inmobiliaria. En C. Delgado Viñas, J. Juaristi Linacero \& S. Tomé Fernández (eds.), Ciudades y paisajes urbanos en el siglo XXI (pp. 241-262). Santander: Estvdio.

Bulkeley, H. \& Betsill, M. (2013). Revisiting the urban politics of climate change. Environmental Politics, 22(1), 136-154. http://dx.doi.org/10.1080/09644016.2013.755797

Burriel de Orueta, E. (2008). La década prodigiosa del urbanismo español (1997-2006). Scripta Nova. Revista Electrónica de Geografía y Ciencias Sociales, 12(270). http://www.ub.es/ geocrit/sn/sn-270/sn-270/sn-270-64.htm

Button, G. V. \& Schuller, M. (2016). Contextualizing disaster. Nueva York / Oxford: Berhahm Books.

Calderón Calderón, B. (2002). Utopía vs. mercado en la construcción de la ciudad finisecular: localismo, exclusión, sostenibilidad y otros paradigmas post. Polígonos, Revista de Geografia, (10), 35-60. http://dx.doi.org/10.18002/pol.v0i10.556

Calderón Calderón, B. (2004). La ciudad del todo urbanizable: estrategias del sector inmobiliario y nuevas e insostenibles formas de urbanización. Revista Ciudades, (8), 135- 155. http://bit.ly/2g4NiOV

Calderón Calderón, B. (2012). Del centralismo a la hipertrofia normativa regional: 1990-2010. Nuevas leyes para ordenar la ciudad. En M. Valenzuela Rubio (coord.), El impacto del modelo autonómico en las ciudades españolas. Una aproximación interdisciplinar (pp. 5796). Madrid: Universidad Autónoma de Madrid (UAM), Col. Estudios. http://dialnet. unirioja.es/servlet/articulo?codigo $=4053780$

Calderón Calderón, B. \& García Cuesta, J. L. (2005). Vaciar la ciudad para llenar la periferia: nuevas estrategias para justificar la ciudad insostenible. En vV.AA., Homenaje a Joaquín González Vecin (pp. 221-231). León: Secretariado de Publicaciones Universidad de León. http://buleria.unileon.es/xmlui/handle/10612/828 
Calderón Calderón, B. \& García Cuesta, J. L. (2017). Legislación urbanística y planeamiento urbano en España, 1998-2015. Del despilfarro a la sostenibilidad. Scripta Nova. Revista Electrónica de Geografia y Ciencias Sociales, 21(570). http://revistes.ub.edu/index.php/ ScriptaNova/article/view/19429

Campesino, A. (2014). Centros y periferias urbanas: ordenación y desgobierno. En R. Lois \& A. Miramontes (eds.), Las ciudades y el sistema urbano. Reflexiones en tiempos de crisis (pp. 91-120). Coruña: Universidad de Santiago de Compostela.

Capel, H. (2016). Las utopías pueden ayudar a construir el futuro. XIV Coloquio Internacional de Geocritica "Las utopias y la construcción de la sociedad del futuro". Barcelona, 2-7 de mayo de 2016. http://www.ub.edu/geocrit/xiv_capeldiscurso.pdf

Carreras, C. \& Moncuende, A. (2016). Marxismos y utopía: viejas y nuevas propuestas urbanas. XIV Coloquio Internacional de Geocritica "Las utopias y la construcción de la sociedad del futuro". Barcelona, 2-7 de mayo de 2016. http://www.ub.edu/geocrit/ xiv_carrerasmorcuende.pdf

Castán Broto, V. \& Bulkeley, H. (2013). A survey of urban climate change experiments in 100 cities. Global Environmental Change, 23(1), 92-102. http://dx.doi.org/10.1016/j. gloenvcha.2012.07.005

Castrillo Romón, Ma . (2010). El urbanismo de renovación de grandes conjuntos de vivienda social en Francia, 2004-2008. Revista Proyecto, Progreso, Arquitectura, (2), 54-67. https://ojs.publius.us.es/ojs/index.php/ppa/article/view/13/21

Castro Orellana, R. (2010). Ciudades ideales, ciudades sin futuro. El porvenir de la utopía. Daimon, Revista Internacional de Filosofía, Suplemento 3, 135-144. http://revistas. um.es/daimon/article/viewFile/119121/112251

Davis, M. (2007). Ciudades muertas: ecología, catástrofe y revuelta. Madrid: Traficantes de Sueños. https://www.traficantes.net/sites/default/files/pdfs/Ciudades\%20muertasTdS.pdf

Delgado, M. (2016). La ciudad ideal como derrota final de lo urbano. Bases místicas de la utopía urbanística y para el asesinato de las ciudades. XIV Coloquio Internacional de Geocritica "Las utopias y la construcción de la sociedad del futuro". Barcelona, 2-7 de mayo de 2016. http://www.ub.edu/geocrit/xiv_manueldelgado.pdf

Deakin, M. (Ed.) (2014). Smart cities: Governing, modelling and analyzing the transition. Nueva York: Routlege.

Downs, A. (2005). Smart growth: Why we discuss it more than we do it. Journal of the American PlanningAssociation, 71(4),367-378.http://dx.doi.org/10.1080/01944360508976707

Frago Ll. \& Martínez, S. (2016). Las utopías urbanas del siglo XIX, herencias y carencias: la carencia social frente la herencia técnica. XIV Coloquio Internacional de Geocrítica "Las utopias y la construcción de la sociedad del futuro". Barcelona, 2-7 de mayo de 2016. http://www.ub.edu/geocrit/xiv_fragomartinez.pdf

Farińa J. \& Naredo, J. M. (2010). Libro Blanco de la sostenibilidad en el planeamiento urbanistico español. Madrid: Ministerio de la Vivienda. http://bit.ly/2xACWlb

Fernández Güell, J. M. (2015). Ciudades inteligentes: la mitificación de las nuevas tecnologías como respuesta a los retos de las ciudades contemporáneas. Economía Industrial, (395), $17-28$.

Fernández, L. D. (2013). Los nuevos rebeldes: artifices de sus propias formas de vida. Buenos Aires: Penguin Random House Grupo Editorial. 
Gaja i Díaz, F. (2015a). Reparar los impactos de la burbuja constructora. Scripta Nova. Revista Electrónica de Geografía y Ciencias Sociales, 19(517). [En línea]. Barcelona: Universidad de Barcelona, 1 de septiembre de 2015, http://www.ub.es/geocrit/sn/sn-517.pdf

Gaja i Díaz, F. (2015b). El nudo gordiano de la regeneración urbana. GeocrtitiQ. http://www. geocritiq.com/2015/11/el-nudo-gordiano-de-la-regeneracion-urbana/

García, C. \& Valero, E. (Coords.) (2016). Intervención en barriadas residenciales obsoletas. Manual de buenas prácticas. Madrid: Abada. http://www.mbpbarriadasobsoletas.com/

Gavinha, J. A. \& Sui, D. Z. (2003). Crecimiento inteligente. Breve historia de un concepto de moda en Norteamérica. Scripta Nova. Revista Electrónica de Geografía y Ciencias Sociales, 7(146/039). Barcelona: Universidad de Barcelona, 1 de agosto de 2003. http://www.ub.es/geocrit/sn/sn-146(039).htm

Leichenko, R. (2011). Climate change and urban resilience. Current Opinion in Environmental Sustainability, (3), 164-168. http://dx.doi.org/10.1016/j.cosust.2010.12.014

Lois, R. C., Piñeira M. J. \& Vives, S. (2016). El proceso urbanizador en España (1990 -2014): una interpretación desde la geografía y la teoría de los circuitos de capital. Scripta Nova. Revista Electrónica de Geografía y Ciencias Sociales, 20(539). [En línea]. Barcelona: Universidad de Barcelona, 1 de julio de 2016. http://www.ub.es/geocrit/sn/sn-539.pdf

Manero Miguel, F. (2009). De la protección selectiva a la recuperación de los espacios urbanos en situación crítica: las áreas de rehabilitación integrada en Castilla y León. Polígonos: Revista de Geografia, (19), 95-118. http://dx.doi.org/10.18002/pol.v0i19.73

Mata Olmo, R. (2007). Auge inmobiliario y evolución de los usos del suelo en España. Por una nueva cultura del territorio. Madrid: Iniversidad Autónoma de Madrid, Lección Inaugural Curso 2007-08. http://bit.ly/2geVLTl

Méndez, R. \& Plaza, J. (2016). Crisis inmobiliaria y desahucios hipotecarios en España: una perspectiva geográfica. Boletin de la Asociación de Geógrafos Españoles, (71), 99-127. http://dx.doi.org/10.21138/bage.2276

Ministerio de Fomento, Gobierno de España (2014). Análisis de las características de la edificación residencial en España en 2011. A nivel nacional y por comunidad autónoma. Madrid. http://bit.ly/2zj6TmU

Ministerio de Fomento, Gobierno de España (s/f). Información estadística | Vivienda y actuaciones urbanas. http://bit.ly/2gsEuTz

Naredo, J. M. (2010). El modelo inmobiliario español y sus consecuencias. Boletín $C F+S$, (44), 13-27. http://habitat.aq.upm.es/boletin/n44/ajnar.html

Nel.lo, O. (1998). Los confines de la ciudad sin confines. Estructura urbana y límites administrativos de la ciudad difusa. En F. G. Monclús (ed.), Urbanismo, ciudad, historia I. La ciudad dispersa. Suburbanización y nuevas periferias (pp. 35-57). Barcelona: Centre de Cultura Contemporania de Barcelona.

Ontiveros, E., Vizcaíno, D. \& López, V. (2016). Las ciudades del futuro: inteligentes, digitales y sostenibles. Madrid: Ariel y Fundación Telefónica. http://bit.ly/2rdj2We

Precedo, A. \& Mínguez, A. (2014). Una radiografía de las ciudades españolas: una evaluación del modelo postindustrial. En R. Lois \& A. Miramontes (eds.), Las ciudades y el sistema urbano. Reflexiones en tiempos de crisis (pp. 15-73). A Coruña: Universidad de Santiago de Compostela. 
Rodríguez Fernández, G. (2005). La ciudad como sede de la imaginación distópica: literatura, espacio y control. Scripta Nova. Revista Electrónica de Geografía y Ciencias Sociales, 9(181). Barcelona: Universidad de Barcelona, 15 de enero de 2005. http://www.ub.es/ geocrit/sn/sn-181.htm

Rogers, R. (2000). Ciudades para un pequeño planeta. Barcelona: Gustavo Gili.

Romero, J. (2010). Construcción residencial y gobierno del territorio en España: de la burbuja especulativa a la recesión. Causas y consecuencias. Cuadernos Geográficos de la Universidad de Granada, (47), 17-46. http://revistaseug.ugr.es/index.php/cuadgeo/ article/view/600/688

Romero, J., Brandis, D. \& Melo, C. (2015). El giro neoliberal de las políticas para la ciudad en España. Balance a partir de los ejemplos de Madrid y Valencia. Boletín de la Asociación de Geógrafos Españoles, (69), 369-386. http://www.age-geografia.es/ojs/index.php/ bage/article/viewFile/1901/1817

Rubio del Val, J. (2011). Rehabilitación urbana en España (1989-2010). Barreras actuales y sugerencias para su eliminación. Informes de la Construcción, (63) (extra, 5-20), 1-20. doi: $10.3989 /$ ic. 11.060

Rubio del Val, J. \& Molina Costa, P. (2010). Estrategias, retos y oportunidades en la rehabilitación de los polígonos de vivienda construidos en España entre 1940 y 1980. Revista Ciudades, (13), 15-37. http://bit.ly/2xAHI21

Ruiz Palomeque, G. (2015). Gestión de la rehabilitación sostenible en grandes conjuntos de las periferias urbanas por las administraciones públicas locales. Informes de la Construcción, (67) (Extra-1), http://dx.doi.org/10.3989/ic.14.047

Serrano, J. M. (2010). La edificación de viviendas en España, final del ciclo y ¿̨ocaso del modelo? Boletín Económico de ICE, (2981), 37-55. http://bit.ly/2kKYXHN

Tapada-Berteli, T. \& Arbaci, S. (2011). Proyectos de regeneración urbana en Barcelona contra la segregación socioespacial (1986-2009): ¿solución o mito? ACE: Architecture, City and Environment, 6(17), 187-222. http://hdl.handle.net/2099/11085

Villarejo Galende, H. (2015). Smart cities. Una apuesta de la Unión Europea para mejorar los servicios públicos urbanos. Revista de Estudios Europeos, (66), 25-51. http://bit. ly/2kMEyT0 